\title{
Application of artificial neural nerworks in oxidation kinetic analysis of nanocomposites
}

\author{
Jerzy Straszko', Anna Biedunkiewicz ${ }^{2}$, Agnieszka Strzelczak ${ }^{1}$ \\ 1 Szczecin University of Technology, Institute of Chemistry and Environmental Protection, al. Piastów 42, \\ 71-065 Szczecin, Poland \\ ${ }^{2}$ Szczecin University of Technology, Institute of Materials Science and Engineering, al. Piastów 19, 70-310 Szczecin, \\ Poland,e-mail:Anna.biedunkiewicz@ps.pl
}

\begin{abstract}
This study concerns the application of artificial neural networks in oxidation kinetic analysis of ceramic nanocomposites. The oxidation of the Ti-Si-C ceramic nanocomposite in dry air was studied. The size of the nanoparticles was determined by scanning electron microscopy (SEM). The gaseous oxidation products were analysed by mass spectroscopy (MS) while the solid oxidation products by X-ray diffraction (XRD). The kinetic analysis of the oxidation was based on the Coats-Redfern equation. The kinetic models were identified for the consecutive stages and then the A and E parameters of the Arrhenius equations were evaluated. Artificial neural networks were used at each step of the kinetic calculations.
\end{abstract}

Keywords: artificial neural networks, ceramic nanocomposites, oxidation, kinetics.

\section{INTRODUCTION}

Modelling of technological processes by structural and non-structural methods is based on data sets with a sufficient number of cases. During the analysis, appropriate input (temperature, concentration of reacting substances etc.) and output variables (conversion degree, conversion rate etc.) should be measured ${ }^{\mathbf{1}}$. The number of variables to record is usually determined on the basis of the theory of the investigated process. In some cases also additional information is needed. Therefore, it should be assessed, if an appropriate number of variables with sufficient accuracy was measured ${ }^{2}$.

In the case of structural models, a process theory is verified by the measurement data and then model parameters are determined with a simultaneous assessment of measurement accuracy. In the case of complex processes this procedure can be of little effectiveness ${ }^{3,4}$. In turn, the non-structural models are created without an explanation of the process mechanism but are based only on the data sets with a sufficient number of cases. Some of the contemporary non-structural methods form separate science disciplines, like the artificial neural networks ${ }^{5-8}$. This method allows verification at each stage of a process modelling ${ }^{\mathbf{9}-11}$.

In this study artificial neural networks were used in the kinetic analysis of the oxidation of the Ti-Si-C ceramic nanocomposite in dry air. That kind of processes is of crucial importance in materials science and engineering ${ }^{\mathbf{9}} \mathbf{2 1}$. The aim was a structural model, based on chemical kinetics and obtained with the help of artificial neural networks.

\section{ARTIFICIAL NEURAL NETWORKS}

Development of neural network technique started from the model of a neuron, elaborated by Mc Culloch and Pitts ${ }^{23}$. The theoretical background of the data transformation systems was formed by Widrow ${ }^{24}$. A dynamic progress in that new field of knowledge was induced by Hopfield and his works ${ }^{25}$. Artificial neural networks are now a separate discipline, used in many financial, medical, environmental and technical science issues.

A neural network is a system of interconnected neurons, which usually form layers: input, output and internal (hid- den). The data set is loaded to the first layer, then, through the existing connections transferred to the next layers. The data obtained from the last layer are the result of calculations. Setting the proper network parameters (wages) of a given neural network is called training. That process requires the data describing the studied phenomena and is performed using appropriate algorithms ${ }^{5-8}$. During the calculations the cases are divided into three subsets: $\operatorname{Tr}$ (used for training), Ve (verifying the training progress) and Te (used for the final testing of a network performance) $)^{5}$.

There are many types of artificial neural networks that differ in their structure and the principle of operation ${ }^{5-8}$. The most popular are multilayer perceptrons (MLP), radial basis function networks (RBF) and generalized regression neural networks (GRNN). MLP neural networks form feedforward architecture of almost any complexity. RBF networks are complementary to MLP- their hidden layers contain radial neurons, which are based on the Cover theorem ${ }^{\mathbf{2 6}}$. In turn, the GRNN neural networks are applicable to regression problems.

In this study Statistical Neural Networks software was used for calculations ${ }^{27-30}$. It contains the Intelligent Problem Solver (IPS) module, which creates a set of neural networks of the best performance. Each model is assessed by the following statistical parameters: Error Mean- average RMS (Root Mean Squared) error value; Abs. E. Meanaverage of absolute error values; Error S.D.- error standard deviation; S.D. Ratio- ratio of error standard deviation and data standard deviation; Correlation- Pearson's correlation coefficient between the target and the predicted data. Statistical assessment is performed separately for the Tr, Ve and the Te subsets. The values of S.D. Ratio lower than 0.1 and Correlation higher than 0.9 describe high-performance models. In complex models with many input variables it is important to indicate the most important factors by sensitivity analysis ${ }^{5}$.

Artificial neural network models must be based on sufficiently large data sets of at least 100 cases. In order to obtain high performance, the analyzed data should be checked for the presence of noise or incomplete cases and, if necessary, scaled or transformed ${ }^{27-30}$. 


\section{MATERIALS AND METHODS}

The studied powder was the Ti-Si-C nanocomposite, obtained by the sol-gel method within the framework of MULTIPROTECT „Advanced Environmentally Friendly Multifunctional Corrosion Protection by Nanotechnology" European Union project ( ${ }^{\circ}$ NMP3-CT-011783). This nanopowder was designed for coatings technology. The chemical and the phase composition were determined by $\mathrm{X}$ ray diffraction (XRD). The measurements were carried out on a Philips X'Pert apparatus with a copper X-ray tube for the wavelength $\mathrm{CuK}_{\alpha}=0.15418 \mathrm{~nm}$, the current voltage of $35 \mathrm{kV}$, the intensity of $30 \mathrm{~mA}$ and the temperature of 298 $\mathrm{K}$. The spectrum analysis was performed using the X'Pert HighScore 1.0 software. TG (thermogravimetric) analyses under non-isothermal conditions were performed on a SETARAM 2915 apparatus in dry air and under atmospheric pressure. The following linear heating rates were applied: $3 \mathrm{~K} / \mathrm{min}$ (sample mass $6.932 \mathrm{mg}$ ); $5 \mathrm{~K} / \mathrm{min}(6.471$ $\mathrm{mg}) ; 10 \mathrm{~K} / \mathrm{min}(7.301 \mathrm{mg}) ; 20 \mathrm{~K} / \mathrm{min}(6.797 \mathrm{mg})$. The TG and DTG curves were recorded. The identification of gaseous oxidation products using mass spectroscopy (MS) supported the division of the process into stages. The measurements were carried out on a Pfeiffer Vacuum apparatus, type Thermostar GSD 301.

\section{MEASUREMENT RESULTS}

The XRD powder diagram of the Ti-Si-C nanocomposite is shown in Figure 1. The following phases were identified: TiC (ICCD card no. 32-1383) and SiC (ICDD card no. 731708). Crystalline carbon was not observed. Thus, we concluded that the carbon matrix had an amorphous form. Proper division of the oxidation process was assured by the analysis of mass spectrums. The gaseous products of the TiC oxidation were carbon oxides $\left(\mathrm{CO}\right.$ and $\left.\mathrm{CO}_{2}\right)$. Additionally, elementary carbon was educed, which is in accordance with former reports ${ }^{31-33}$. During the oxidation of the $\mathrm{SiC}$ phase only the gaseous products (carbon oxides) were produced. $\mathrm{CO}$ and $\mathrm{CO}_{2}$ spectral lines had the same course, therefore in Figure 2 only the spectral line m/e 44 is shown. In Figure 3 the normalized TG curves are shown, obtained by dividing an actual sample mass by the initial sample mass. They were assessed by artificial neural networks. All the series of the measurements were considered jointly. The output variable was the normalized TG while the input variables were sample heating rate and temperature. The obtained model was the GRNN 2/12306 neural network, which statistical assessment is given in Table 1 . The high performance of the model indicated the good quality of the measurement data. Therefore, they could be applied in further calculations.

First, the process was divided into stages ${ }^{\mathbf{1}, 11}$. The distinguished conversions are given in Table 2. Stage II concerned the combustion of elementary carbon educed in stage I (oxidation of TiC) while stage III the combustion of carbon matrix. Then, the $\alpha(\mathrm{T})$ functions were determined (Figure 4), according to the methodology reported by Straszko et $\mathrm{al}^{1 \mathbf{1 1}}$. They were assessed with the help of artificial neural networks. The obtained models and their statistical assessment are given in Table 3. Good accuracy in all the cases confirmed that, in accordance with the theory, the conversion degree depended on sample heating rate and the temperature and could be used in further kinetic calculations.

Table 1. Statistical assessment of GRNN 2/12306 neural model with norm. TG as dependent

\begin{tabular}{|c|c|c|c|}
\hline Parameter & $\mathrm{Tr}$ & $\mathrm{Ve}$ & $\mathrm{Te}$ \\
\hline Error Mean & 0.0001 & 0.0001 & 0.0001 \\
\hline Error S.D. & 0.0008 & 0.0008 & 0.0008 \\
\hline Abs E. Mean & 0.0004 & 0.0004 & 0.0004 \\
\hline S.D. Ratio & 0.0430 & 0.0436 & 0.0419 \\
\hline Correlation & 0.999 & 0.999 & 0.999 \\
\hline
\end{tabular}

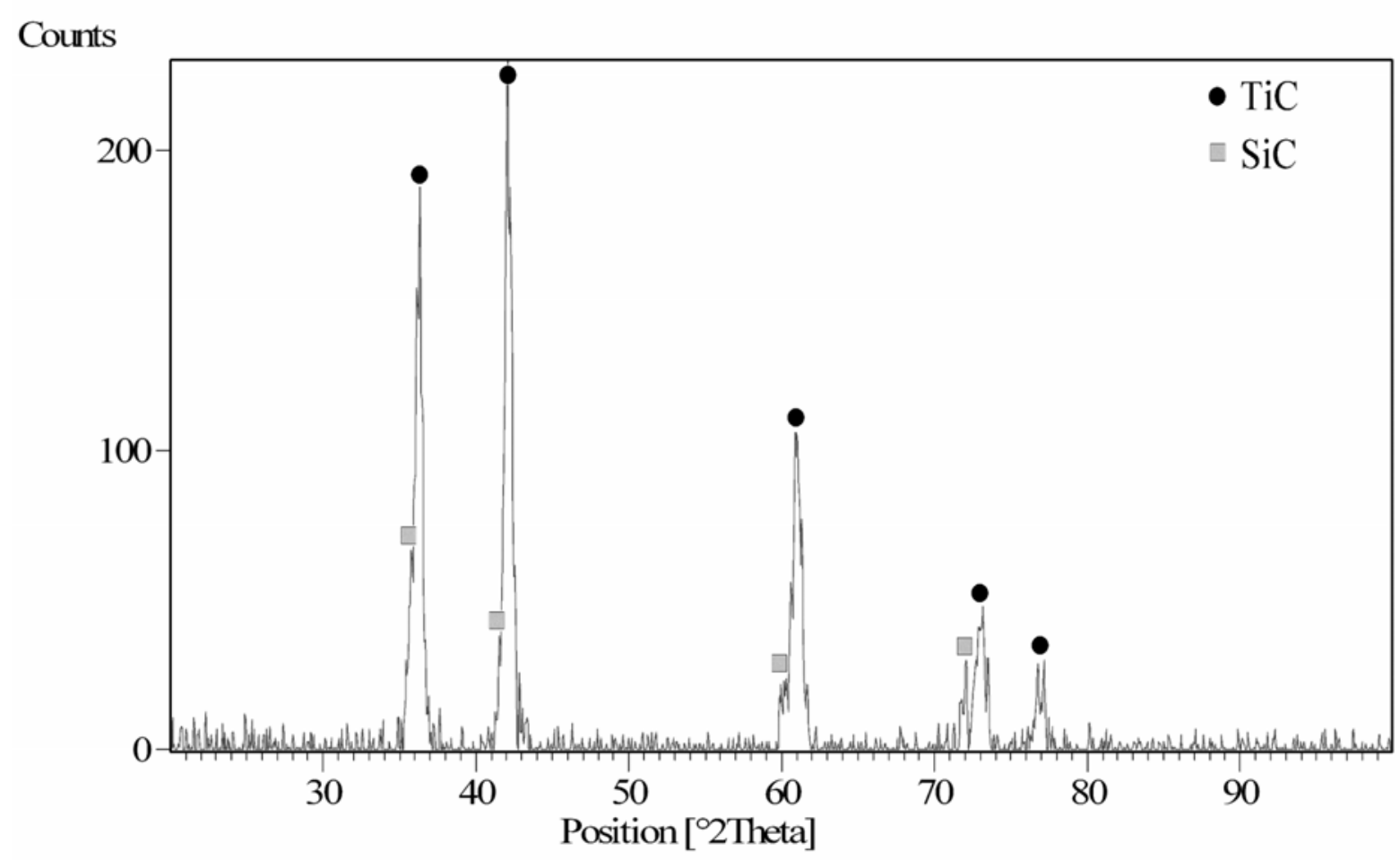

Figure 1. XRD powder diagram of Ti-Si-C nanocomposite 
a)

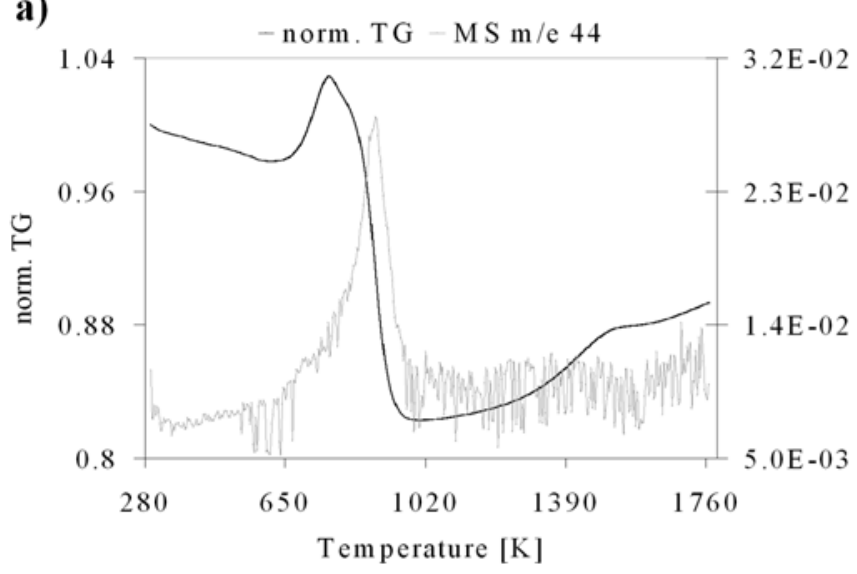

c)

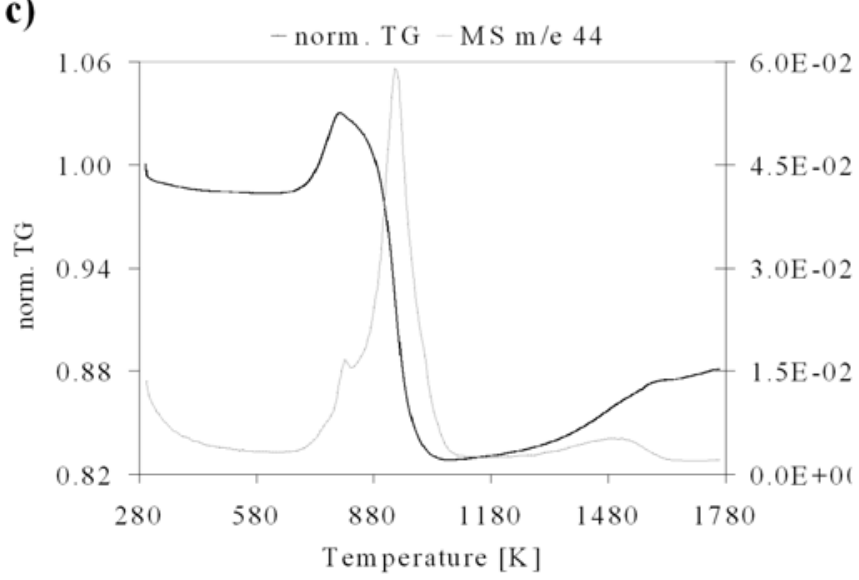

b)
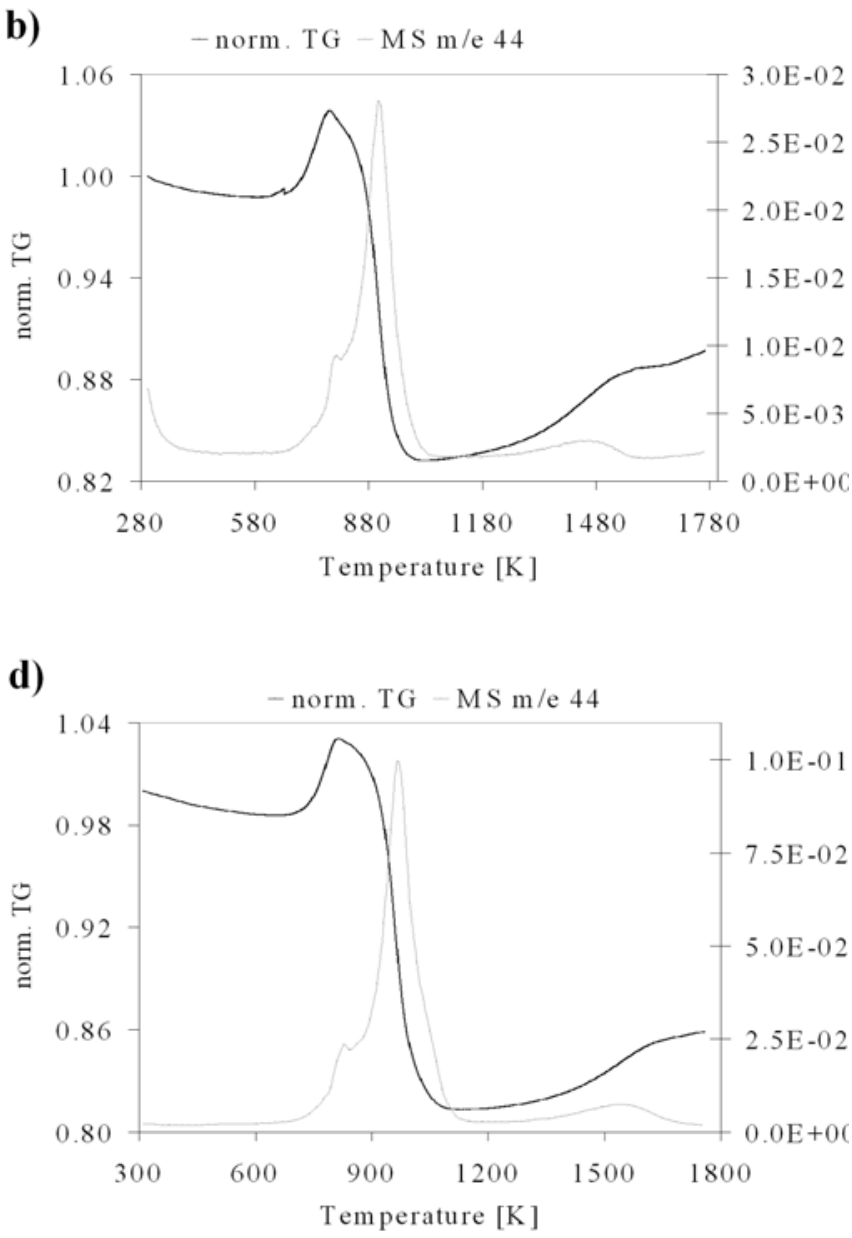

Figure 2. Spectral lines $\mathrm{m} / \mathrm{e} 44$ and normalized TG curves recorded during oxidation of Ti-Si-C powder with the heating rate of a) $3 \mathrm{~K} / \mathrm{min}$, b) $5 \mathrm{~K} / \mathrm{min}$, c) $10 \mathrm{~K} / \mathrm{min}$, d) $20 \mathrm{~K} / \mathrm{min}$

Table 2. Temperature ranges and processes occurring in the consecutive stages of oxidation of Ti-Si-C nanocomposite

\begin{tabular}{|c|c|c|c|}
\hline Stage & Process & $\beta[\mathrm{K} / \mathrm{min}]$ & $\begin{array}{c}\text { Temperature range } \\
{[\mathrm{K}]}\end{array}$ \\
\hline \multirow{4}{*}{0} & \multirow{4}{*}{ Desorption of impurities } & 3 & $296-620$ \\
\hline & & 5 & $298-600$ \\
\hline & & 10 & $298-600$ \\
\hline & & 20 & $300-650$ \\
\hline \multirow{4}{*}{ I } & \multirow{4}{*}{ Oxidation of $\mathrm{TiC}$} & 3 & $639-764$ \\
\hline & & 5 & $661-773$ \\
\hline & & 10 & $654-792$ \\
\hline & & 20 & $686-810$ \\
\hline \multirow{4}{*}{ II } & \multirow{4}{*}{ Combustion of $\mathrm{C}_{\mathrm{el}}$} & 3 & $775-820$ \\
\hline & & 5 & $785-837$ \\
\hline & & 10 & $801-853$ \\
\hline & & 20 & $826-887$ \\
\hline \multirow{4}{*}{ III } & \multirow{4}{*}{ Combustion of $\mathrm{C}_{\text {matr }}$} & 3 & $831-985$ \\
\hline & & 5 & $848-1001$ \\
\hline & & 10 & $867-1054$ \\
\hline & & 20 & $927-1104$ \\
\hline \multirow{4}{*}{ IV } & \multirow{4}{*}{ Osidation of $\mathrm{SiC}$} & 3 & $1045-1558$ \\
\hline & & 5 & $1073-1590$ \\
\hline & & 10 & $1111-1640$ \\
\hline & & 20 & $1187-1677$ \\
\hline
\end{tabular}

\section{KINETIC ANALYSIS}

The kinetic analysis of non-isothermal oxidation in this study was based on the Coats-Redfern linear equation ${ }^{22}$ :

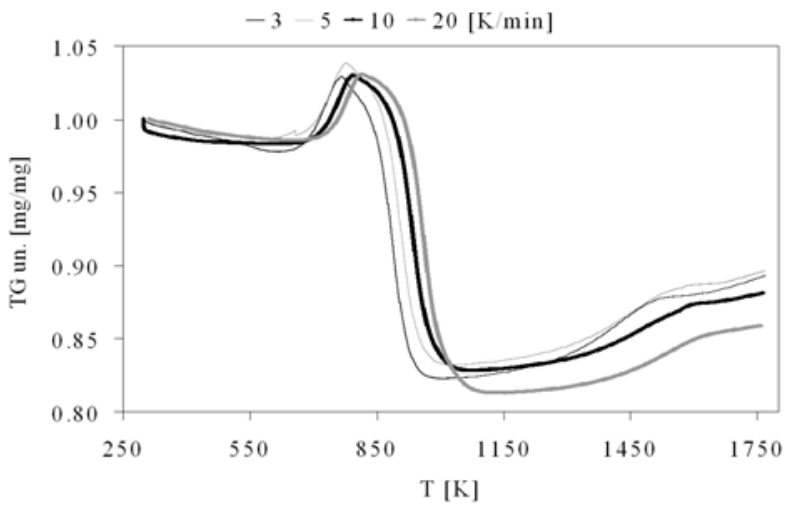

Figure 3. Normalized TG curves from oxidation of Ti-Si-C nanocomposite

$\ln \left(\frac{\mathrm{g}(\alpha)}{\mathrm{T}^{2}}\right)=\ln \left\{\frac{\mathrm{AR}}{\beta \mathrm{E}}\left(1-\frac{2 \mathrm{RT}_{\mathrm{m}}}{\mathrm{E}}\right)\right\}-\frac{\mathrm{E}}{\mathrm{RT}}$

As a theoretical equation it cannot be sufficiently satisfied in the case of real processes, which are affected by the changes in particle size and their geometry or formation of the solid products $^{30-33}$. As a result, deviations from linearity hamper the identification of the kinetic models and the determination of kinetic parameters $A$ and $E^{34,35}$. Structural models are usually assessed by statistical methods. Simple statistical tests are often insufficient and residue analysis is important. Distribution of residues depends on the quality of both the measurement data and the model performance ${ }^{8}$. 
Table 3. Statistical assessment of neural models with conversion degree as dependent variable

\begin{tabular}{|c|c|c|c|c|c|c|}
\hline \multirow{2}{*}{ Parameter } & $\mathrm{Tr}$ & $\mathrm{Ve}$ & $\mathrm{Te}$ & $\mathrm{Tr}$ & $\mathrm{Ve}$ & $\mathrm{Te}$ \\
\hline & \multicolumn{3}{|c|}{ Stage I, MLP 2/4 } & \multicolumn{3}{|c|}{ Stage II, MLP 2/3 } \\
\hline Error Mean & -0.00001 & -0.00004 & 0.00024 & 0.00000 & 0.00016 & 0.00093 \\
\hline Error S.D. & 0.00671 & 0.00658 & 0.00681 & 0.00851 & 0.00891 & 0.00862 \\
\hline Abs E. Mean & 0.00536 & 0.00528 & 0.00532 & 0.00690 & 0.00721 & 0.00714 \\
\hline S.D. Ratio & 0.02130 & 0.02090 & 0.02130 & 0.03024 & 0.03125 & 0.03021 \\
\hline \multirow[t]{2}{*}{ Correlation } & 0.999 & 0.999 & 0.999 & 0.999 & 0.999 & 0.999 \\
\hline & \multicolumn{3}{|c|}{ Stage III. MLP 2/3 } & \multicolumn{3}{|c|}{ Stage IV. MLP 2/3 } \\
\hline Error Mean & -0.00005 & 0.00002 & 0.00006 & 0.00001 & -0.00009 & -0.00038 \\
\hline Error S.D. & 0.00422 & 0.00471 & 0.00484 & 0.00669 & 0.00684 & 0.00689 \\
\hline Abs E. Mean & 0.00238 & 0.00262 & 0.00264 & 0.00436 & 0.00464 & 0.00463 \\
\hline S.D. Ratio & 0.01229 & 0.01377 & 0.01403 & 0.01992 & 0.02038 & 0.02048 \\
\hline Correlation & 0.999 & 0.999 & 0.999 & 0.999 & 0.999 & 0.999 \\
\hline
\end{tabular}

a)

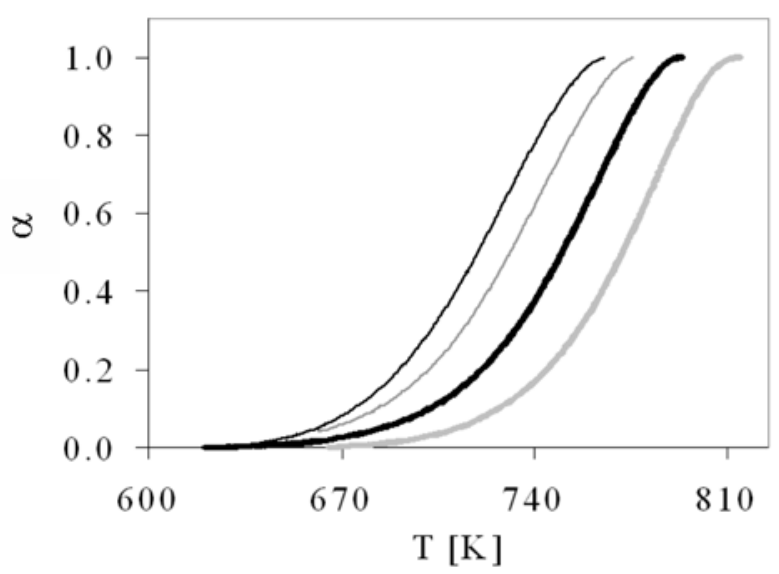

c)

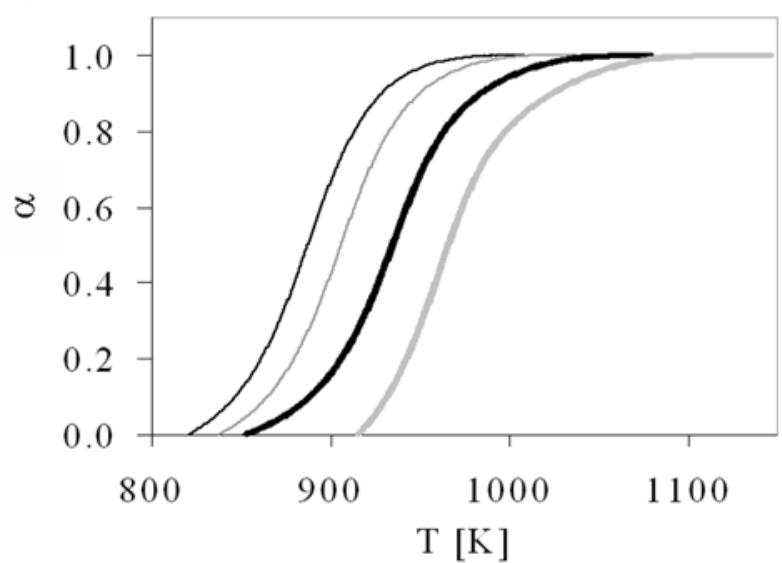

b) $-3-5-10-20[\mathrm{~K} / \mathrm{m}$ in $]$

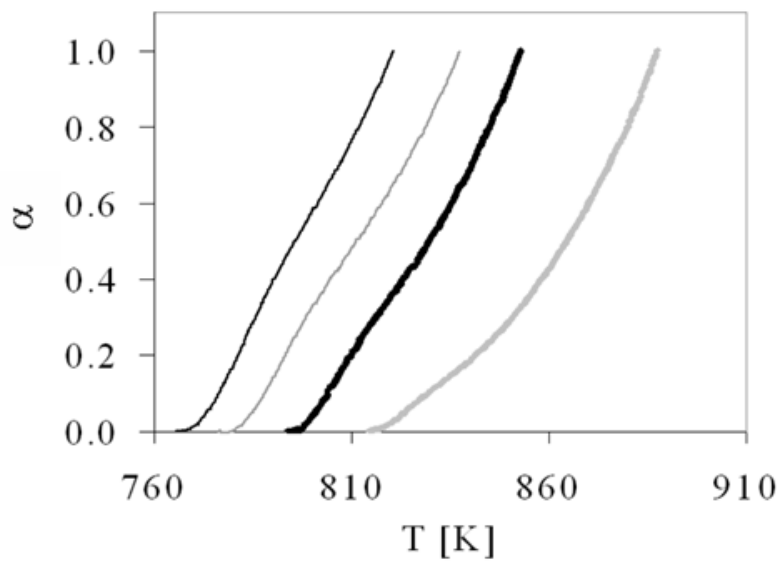

d) $-3-5-10-20[\mathrm{~K} / \mathrm{m}$ in $]$

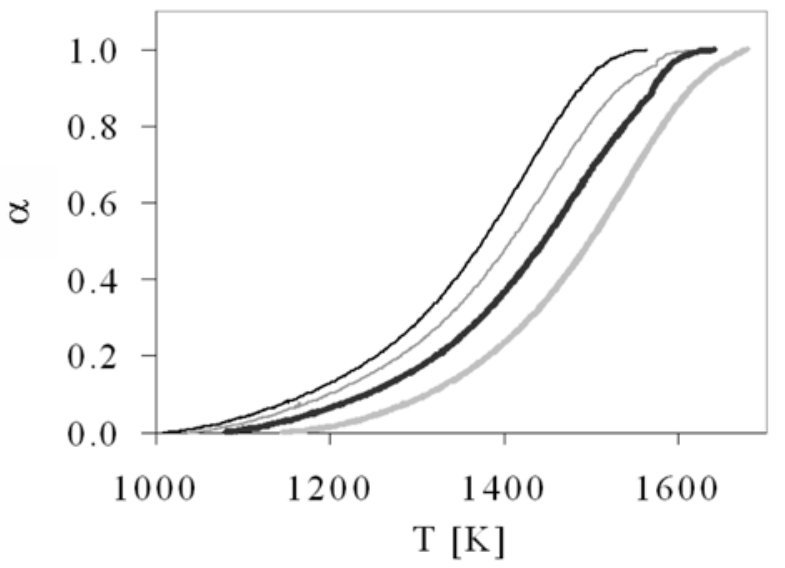

Figure 4. Dependence of conversion degree on temperature in the distinguished stages of Ti-Si-C oxidation. a) stage I; b) stage II; c) stage III; d) stage IV

The following kinetic models were tested in this study: D1 (one-dimensional diffusion), D2 (two-dimensional diffusion, cylindrical symmetry), D3 (three-dimensional diffusion, spherical symmetry, Jander equation), D4 (three-dimensional diffusion, spherical symmetry, Ginstling-Brounshtein equation), F1 (first-order reaction), F2 (second-order reaction), F3 (third-order reaction), A2 (random nucleation, Avrami I equation), A3 (random nucleation, Avrami II equation), R1 (phase-boundary reaction, zero-order reaction), R2 (phaseboundary reaction, cylindrical symmetry), and R3 (phaseboundary reaction, spherical symmetry. The preliminary assumption was the fulfilment of linearity in the co-ordinate system $\ln \left(\frac{g(\alpha)}{T^{2}}\right)-\frac{1000}{T}$. The accuracy of the fit was assessed by linear regression using Statgraf software, separately for the consecutive series of the measurements. Additionally, the fulfilment of the Coats-Redfern equation was evaluated with the linear neural network models, using StatSoft software STATISTICA Neural Networks 4.0A. In that case, all the series of the measurements were considered jointly under the assumption that the A and E parameters should be constant and independent of the process conditions. The input variable was sample heating rate and $\frac{1000}{T}$ while the output 
variable was $\ln \left(\frac{\mathrm{g}(\alpha)}{\mathrm{T}^{2}}\right)$ function. The performance of the linear neural network models was assessed by the Pearson's correlation coefficient between the experimental and the predicted data, and also by the SD Ratio. Those parameters were calculated separately for the training $(\mathrm{Tr})$, verification (Ve) and the testing (Te) subsets.

The kinetic parameters were first determined by means of linear regression for each series of the measurements separately. Because of the deviations from linearity the $\ln \left(\frac{\mathrm{g}(\alpha)}{\mathrm{T}^{2}}\right)-\frac{1000}{\mathrm{~T}}$ lines had different slopes and as a result different $\mathrm{A}$ and $\mathrm{E}$ values between the measurement series. Moreover, the residues were independent random variables and correlations between $\ln \mathrm{A}$ and $\mathrm{E}$ were observed. There were also difficulties in the identification of the kinetic models. Therefore, it was supported by additional criteria. It was required that linearity in all the series of the measurements was fulfilled for the same $g(\alpha)$ function. The courses of $k(T)$ dependencies had to be convergent in spite of the differences in the $\mathrm{A}$ and $\mathrm{E}$ values between the series. The parameters of the Arrhenius equation, calculated from a given model by means of linear regression, were adjusted by stochastic linearization ${ }^{39}$, i.e. correction of the $\mathrm{E}$ value so that the error in a series approached zero. Finally, consistency in a wide range between the $\alpha(\mathrm{T})$ values calculated from the Coats-Redfern equation and determined from the measurements was demanded. The methodology of the calculations is shown in the example of stage I.

The linearity condition was quite well fulfilled for models D3, F1 and R3. The fit was assessed with the help of neural networks. Good accuracy was obtained for all the considered models (Table 4), therefore the A and E parameters were calculated from each of them. The linear regression analysis was performed separately for the consecutive measurement series using Statgraf software. The results with statistical assessment are given in Table 5. Still the unambiguous choice of the best model could not be made. Therefore, an additional criterion was used- the convergence of $k(T)$. This requirement was fulfilled by model F1.

Using the $\mathrm{A}$ and $\mathrm{E}$ parameters, given in Table 5, the values of the $\ln \left(\frac{\mathrm{g}(\alpha)}{\mathrm{T}^{2}}\right)$ function were calculated from the Coats-

Redfern equation. Considerable errors were obtained in spite of good statistical assessment. The values of the E parameter were slightly corrected until the errors in the series were close to 0 . The results are shown in Table 6 . Using the corrected kinetic parameters, $\alpha(\mathrm{T})$ dependencies were calculated from the Coats-Redfern equation and compared with the empirical values (Figure 5). Finally, it was assumed that stage I (oxidation of TiC) proceeded according to model F1 with corrected kinetic parameters given in Table 6 .

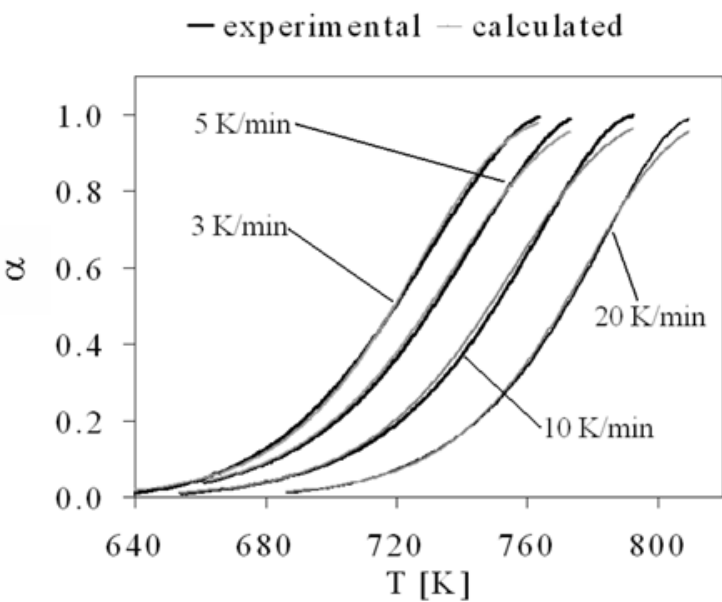

Figure 5. Comparison of experimental a(T) functions and those calculated from kinetic models for stage I of Ti-Si-C oxidation

Table 4. Statistical assessment of neural networks. Kinetic models in stage I of Ti-Si-C oxidation

\begin{tabular}{|c|c|c|c|c|c|c|c|c|c|}
\hline \multirow{2}{*}{ Parametr } & \multicolumn{3}{|c|}{ Model D3 } & \multicolumn{3}{|c|}{ Model F1 } & \multicolumn{3}{|c|}{ Model R3 } \\
\hline & $\mathrm{Tr}$ & $\mathrm{Ve}$ & $\mathrm{Te}$ & $\mathrm{Tr}$ & $\mathrm{Ve}$ & $\mathrm{Te}$ & $\operatorname{Tr}$ & $\mathrm{Ve}$ & $\mathrm{Te}$ \\
\hline Error Mean & 0.0000 & 0.0206 & -0.0029 & 0.0000 & 0.0092 & 0.0085 & 0.0000 & 0.0092 & -0.0032 \\
\hline Error S.D. & 0.3185 & 0.3219 & 0.3248 & 0.1505 & 0.1648 & 0.1581 & 0.1574 & 0.1644 & 0.1648 \\
\hline Abs E. Mean & 0.2626 & 0.2680 & 0.2674 & 0.1199 & 0.1308 & 0.1270 & 0.1284 & 0.1359 & 0.1339 \\
\hline S.D. Ratio & 0.1150 & 0.1168 & 0.1179 & 0.1036 & 0.1116 & 0.1084 & 0.1183 & 0.1229 & 0.1237 \\
\hline Correlation & 0.993 & 0.993 & 0.993 & 0.995 & 0.994 & 0.994 & 0.993 & 0.992 & 0.992 \\
\hline
\end{tabular}

Table 5. Kinetic parameters for the consecutive series of measurements in stage I of Ti-Si-C oxidation

\begin{tabular}{|c|c|c|c|c|c|c|c|c|}
\hline$\beta[\mathrm{K} / \mathrm{min}]$ & Model & $r^{*}$ & $F$ & $\mathrm{~T}_{\mathrm{m}}[\mathrm{K}]$ & $\mathrm{E}[\mathrm{kJ} / \mathrm{mol}]$ & $\mathrm{A}[1 / \mathrm{min}]$ & $\Delta \alpha$ & $\Delta \mathrm{T}[\mathrm{K}]$ \\
\hline \multirow{3}{*}{3} & D3 & 0.995 & 95173.08 & \multirow{3}{*}{719.6} & 322.84 & $3.59 \mathrm{E}+21$ & \multirow{3}{*}{$0.01-0.99$} & \multirow{3}{*}{$639-764$} \\
\hline & F1 & 0.998 & 318832.10 & & 170.71 & $2.24 \mathrm{E}+11$ & & \\
\hline & R3 & 0.994 & 87117.09 & & 155.61 & $1.38 \mathrm{E}+10$ & & \\
\hline \multirow{3}{*}{5} & D3 & 0.999 & 318832.10 & \multirow{3}{*}{731.2} & 292.82 & $1.73 E+19$ & \multirow{3}{*}{$0.04-0.99$} & \multirow{3}{*}{$661-773$} \\
\hline & $\mathrm{F} 1$ & 0.999 & 318832.10 & & 157.02 & $2.31 \mathrm{E}+10$ & & \\
\hline & R3 & 1.000 & 1803161.00 & & 140.47 & $1.13 \mathrm{E}+09$ & & \\
\hline \multirow{3}{*}{10} & D3 & 1.000 & 1027132.00 & \multirow{3}{*}{750.4} & 321.53 & $1.11 \mathrm{E}+21$ & \multirow{3}{*}{$0.01-0.99$} & \multirow{3}{*}{$654-792$} \\
\hline & $\mathrm{F} 1$ & 0.998 & 200468.10 & & 168.72 & $1.65 E+11$ & & \\
\hline & R3 & 1.000 & 910379.80 & & 154.79 & $1.33 \mathrm{E}+10$ & & \\
\hline \multirow{3}{*}{20} & D3 & 0.999 & 354398.70 & \multirow{3}{*}{772.2} & 376.36 & $2.88 \mathrm{E}+24$ & \multirow{3}{*}{$0.01-0.99$} & \multirow{3}{*}{$686-810$} \\
\hline & $\mathrm{F} 1$ & 0.999 & 320315.80 & & 198.34 & $1.47 \mathrm{E}+13$ & & \\
\hline & R3 & 0.999 & 322624.00 & & 181.98 & $9.97 \mathrm{E}+11$ & & \\
\hline
\end{tabular}


Table 6. Kinetic parameters before and after correction. Oxidation of Ti-Si-C nanocomposite in stage I

\begin{tabular}{|l|c|c|c|c|c|}
\hline \multirow{2}{*}{$\beta[\mathrm{K} / \mathrm{min}]$} & \multirow{2}{*}{$\mathrm{A}[1 / \mathrm{min}]$} & \multicolumn{2}{|c|}{ before correction } & \multicolumn{2}{|c|}{ after correction } \\
\cline { 3 - 6 } & & $\mathrm{E}[\mathrm{kJ} / \mathrm{mol}]$ & $\mathrm{Error}[\%]$ & $\mathrm{E}[\mathrm{kJ} / \mathrm{mol}]$ & \multicolumn{2}{c|}{ Error $[\%]$} \\
\hline 3 & $2.24 \mathrm{E}+11$ & 170.71 & -7.1 & 164.81 & 0.0093 \\
\hline 5 & $2.31 \mathrm{E}+10$ & 157.02 & -6.4 & 151.68 & 0.0093 \\
\hline 10 & $1.65 \mathrm{E}+11$ & 168.72 & -6.6 & 162.99 & -0.0001 \\
\hline 20 & $1.47 \mathrm{E}+13$ & 198.34 & -8.3 & 190.52 & 0.0005 \\
\hline
\end{tabular}

Table 7. Kinetic parameters obtained for all stages of the Ti-Si-C oxidation process

\begin{tabular}{|c|c|c|c|c|c|c|c|}
\hline Stage & Model & $\beta[\mathrm{K} / \mathrm{min}]$ & $\mathrm{A}[1 / \mathrm{min}]$ & $\mathrm{E}[\mathrm{kJ} / \mathrm{mol}]$ & $\mathrm{Tm}[\mathrm{K}]$ & $\Delta \mathrm{T}[\mathrm{K}]$ & $\Delta \alpha$ \\
\hline \multirow{5}{*}{1} & \multirow{5}{*}{$\mathrm{F} 1$} & 3 & $2.24 \mathrm{E}+11$ & 164.81 & 719.6 & $639-764$ & $0.01-0.99$ \\
\hline & & 5 & $2.31 \mathrm{E}+10$ & 151.68 & 731.2 & $661-773$ & $0.04-0.99$ \\
\hline & & 10 & $1.65 \mathrm{E}+11$ & 162.99 & 750.4 & $654-792$ & $0.01-0.99$ \\
\hline & & 20 & $1.47 \mathrm{E}+13$ & 190.82 & 772.2 & $686-810$ & $0.01-0.99$ \\
\hline & & Mean & $3.35 \mathrm{E}+11$ & 173.70 & & & \\
\hline \multirow{5}{*}{ II } & \multirow{5}{*}{ F1 } & 3 & $2.85 \mathrm{E}+22$ & 345.75 & 795.7 & $775-820$ & $0.07-0.99$ \\
\hline & & 5 & $3.35 \mathrm{E}+20$ & 319.96 & 811.4 & $785-837$ & $0.05-0.99$ \\
\hline & & 10 & $3.67 \mathrm{E}+21$ & 338.20 & 829.8 & $801-853$ & $0.05-0.99$ \\
\hline & & 20 & $9.39 \mathrm{E}+18$ & 306.07 & 864.7 & $826-887$ & $0.07-0.98$ \\
\hline & & Mean & $7.57 \mathrm{E}+20$ & 337.33 & & & \\
\hline \multirow{5}{*}{ III } & \multirow{5}{*}{$\mathrm{F} 2$} & 3 & $9.81 \mathrm{E}+20$ & 357.51 & 887.3 & $831-985$ & $0.03-0.99$ \\
\hline & & 5 & $1.12 \mathrm{E}+20$ & 346.16 & 906.0 & $848-1001$ & $0.03-0.99$ \\
\hline & & 10 & $5.80 \mathrm{E}+18$ & 329.85 & 935.0 & $867-1054$ & $0.03-0.99$ \\
\hline & & 20 & $1.09 \mathrm{E}+19$ & 342.68 & 966.3 & $927-1104$ & $0.06-0.99$ \\
\hline & & Mean & $5.13 \mathrm{E}+19$ & 355.31 & & & \\
\hline \multirow{5}{*}{ IV } & \multirow{5}{*}{ D3 } & 3 & $6.08 \mathrm{E}+06$ & 239.24 & 1375.2 & $1045-1558$ & $0.01-0.99$ \\
\hline & & 5 & $5.07 \mathrm{E}+06$ & 238.74 & 1407.5 & $1073-1590$ & $0.01-0.99$ \\
\hline & & 10 & $3.70 \mathrm{E}+07$ & 259.28 & 1445.8 & $1111-1640$ & $0.01-0.99$ \\
\hline & & 20 & $2.70 \mathrm{E}+09$ & 310.30 & 1498.8 & $1187-1677$ & $0.01-0.99$ \\
\hline & & Mean & $4.19 \mathrm{E}+07$ & 266.13 & & & \\
\hline
\end{tabular}

Table 8. Kinetic parameters evaluated with linear neural networks for the consecutive stages of $\mathrm{Ti}-\mathrm{Si}-\mathrm{C}$ oxidation

\begin{tabular}{|c|c|c|c|c|}
\hline Stage & Model & $\mathrm{A}[1 / \mathrm{min}]$ & $\mathrm{E}[\mathrm{kJ} / \mathrm{mol}]$ & Correlation \\
\hline I & $\mathrm{F} 1$ & $1.62 \mathrm{E}+11$ & 167.99 & 0.994 \\
\hline II & F1 & $3.80 \mathrm{E}+23$ & 379.79 & 0.980 \\
\hline III & F2 & $6.09 \mathrm{E}+19$ & 356.88 & 0.997 \\
\hline IV & D3 & $7.88 \mathrm{E}+06$ & 247.19 & 0.993 \\
\hline
\end{tabular}

The calculations for the remaining stages were performed in the same way and their final results are shown in Table 7. The values of the E and A parameters differed between the measurement series. This situation is caused by the deviations from linearity and hampers the estimation of the actual $A$ and $E$ values. Under the assumption, that $\ln A$ and $E$ fulfill the normality condition, arithmetic means are their estimates. However, having only a few series of measurements, the normality may not be obtained.

Another way of evaluating the actual kinetic parameters consists in the application of artificial neural networks. The linear models generate in the $\ln \left(\frac{\mathrm{g}(\alpha)}{\mathrm{T}^{2}}\right)-\frac{1000}{\mathrm{~T}}$ co-ordinate system parallel lines for the consecutive sample heating rates. If the deviations from linearity are not considerable, sing $\ln \left(\frac{g(\alpha)}{T^{2}}\right)$ values calculated by a linear network a set of $A$ and

E values are obtained, the same for all the series. The results of this kind of the calculations for the consecutive stages of Ti-Si-C oxidation are given in Table 8 .

It should be underlined, that in spite of the different $A$ and E values evaluated with both methods, similar k (T) plots
- experimental - calculated

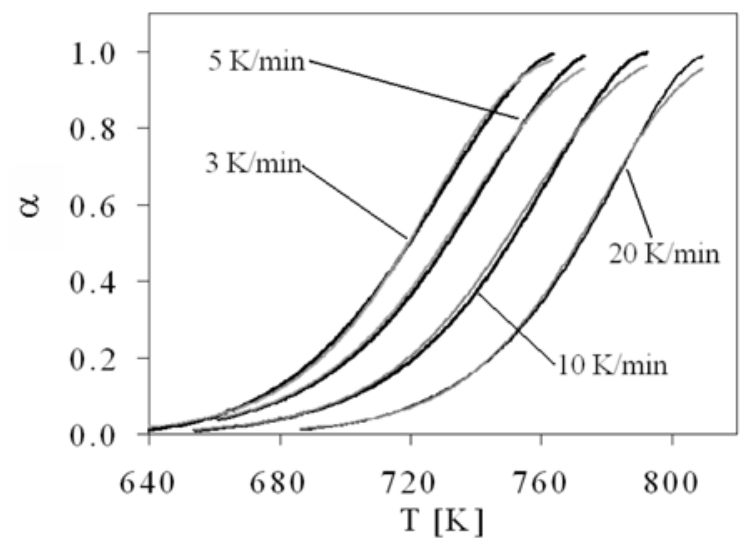

Figure 6. SEM images of titanium dioxide obtained in the hydrolysis of titanyl sulfate from a solution with the initial $\mathrm{Al}^{3+}$ concentration equal to: a) $0.07 \mathrm{wt}$ $\%$, b) 0.3 wt $\%$

were obtained. The results from the linear network were assumed to be the proper ones, in accordance with former reports $^{30-33,36-38}$ and are the starting point for the process analysis $^{1,11,21}$.

\section{SUMMARY}

Ceramic nanocomposites can be applied in various technological processes, where quantitative description is needed. Due to the peculiarity of nanostructure material traditional methods may not be sufficient. Quantitative description of technological processes, usually in the form of structural models, is obtained on the basis of the experimental data with a simultaneous assessment of the underlying theory, the 
model parameters and the measurement quality. In the case of complex processes this system may be of little effectiveness and then non-structural methods are more useful, for instance the artificial neural networks. This paper is an example of an application of neural models in oxidation kinetic analysis. Neural models were used in the measurement quality assessment as well as in the identification of kinetic models and kinetic parameters estimation. The obtained results were of high accuracy and proved applicability of artificial neural networks in the discussed type of analysis.

\section{NOMENCLATURE}

A - pre-exponential Arrhenius factor, $1 / \mathrm{min}$

E - apperent activation energy, $\mathrm{kJ} / \mathrm{mol}$
$\mathrm{k}(\mathrm{T})$ - rate constant, $1 / \mathrm{min}$

$\mathrm{r} \quad-$ rection rate, $1 / \mathrm{min}$

$\mathrm{T}-$ temperature, $\mathrm{K}$

$\mathrm{T}_{\mathrm{m}}-$ maximum conversion rate temperature, $\mathrm{K}$

$\alpha(\mathrm{T})$ - conversion degree

B - sample heating rate, $\mathrm{K} / \mathrm{min}$

$\mathrm{r}^{*}$ - correlation coefficient

$\mathrm{R} \quad-$ gas constant, $\mathrm{kJ} / \mathrm{molK}$

$\mathrm{t}$ - time, min

$\mathrm{F}-$ - Snedecor's variable

$f(\alpha)-$ conversion function dependent on mechanism of the reaction

$g(\alpha)$ - integral form of the conversion function

\section{TESTED KINETIC MODELS}

\begin{tabular}{|c|c|c|c|}
\hline Mechanism & Symbol & $f(\alpha)$ & $g(\alpha)$ \\
\hline One-dimensional diffusion & D1 & $\alpha^{-1}$ & $\alpha^{2}$ \\
\hline Two-dimensional diffusion, cylindrical symmetry & D2 & {$[-\ln (1-\alpha)]^{-1}$} & $(1-\alpha) \ln (1-\alpha)+\alpha$ \\
\hline $\begin{array}{l}\text { Three-dimensional diffusion, spherical symmetry, Jander } \\
\text { equation }\end{array}$ & D3 & $\frac{(1-\alpha)^{2 / 3}}{1-(1-\alpha)^{1 / 3}}$ & $\frac{3}{2}\left[1-(1-\alpha)^{1 / 3}{ }^{2}\right]$ \\
\hline $\begin{array}{l}\text { Three-dimensional diffusion, spherical symmetry, Ginstling- } \\
\text { Brounshtein equation }\end{array}$ & D4 & {$\left[(1-\alpha)^{-1 / 3}-1^{-1}\right]$} & $\frac{3}{2}\left[1-\frac{2}{3} \alpha-(1-\alpha)^{2 / 3}\right.$ \\
\hline $1^{\text {st }}$ order reaction & $\mathrm{F} 1$ & $(1-\alpha)$ & {$[-\ln (1-\alpha)]$} \\
\hline $2^{\text {nd }}$ order reaction & $\mathrm{F} 2$ & $(1-\alpha)^{2}$ & $(1-\alpha)^{-1}-1$ \\
\hline $3^{\text {rd }}$ order reaction & F3 & $\frac{1}{2}(1-\alpha)^{3}$ & $(1-\alpha)^{-2}-1$ \\
\hline Random nucleation, Avrami I equation & $\mathrm{A} 2$ & $(1-\alpha)[-\ln (1-\alpha)]^{1 / 2}$ & {$[-\ln (1-\alpha)]^{1 / 2}$} \\
\hline Random nucleation, Avrami II equation & A3 & $(1-\alpha)[-\ln (1-\alpha)]^{2 / 3}$ & {$[-\ln (1-\alpha)]^{1 / 3}$} \\
\hline Phase-boundary reaction, zero-order reaction & $\mathrm{R} 1$ & 1 & $\alpha$ \\
\hline Phase-boundary reaction, cylindrical symmetry & $\mathrm{R} 2$ & $(1-\alpha)^{1 / 2}$ & $21-(1-\alpha)^{1 / 2}$ \\
\hline Phase-boundary reaction, spherical symmetry & R3 & $(1-\alpha)^{2 / 3}$ & $31-(1-\alpha)^{1 / 3}$ \\
\hline
\end{tabular}

\section{LITERATURE CITED}

1. Strzelczak, A. (2008). Analysis of oxidation processes of selected ceramic nanocomposites in dry air. Unpublished doctoral dissertation, Szczecin University of Technology, Poland. (In Polish).

2. Bykowszczenko, N. (2007). Identification of air contamination models in industrial regions. Unpublished doctoral dissertation, Szczecin University of Technology, Poland. (In Polish).

3. Kamiński, W., Strumiłłom, P. \& Toczek, E. (2005). Application of artificial intelligence systems in solving selected air protection problems. PAN, Łódź. (In Polish).

4. Gajda, J.B. (2001). Prognoses and simulations versus economic decisions. Wydawnictwo Beck, Warszawa. (In Polish)

5. Osowski, S. (1996). Neural networks in algorithmic approach. WNT, Warszawa. (In Polish).
6. Tadusiewicz, R. (1993). Neural networks. Akademicka Oficyna Wydawnicza, Warszawa. (In Polish).

7. Żurada, J., Barski, M. \& Jędrych, W. (1996). Artificial neural networks. PWN, Warszawa. (In Polish).

8. Piegat, S. (2003). Fuzzy modelling and control. EXIT, Warszawa. (In Polish).

9. Straszko, J., Chrościechowska, J. \& Stankiewicz, D. (2006). Analysis of thermal decomposition of $\mathrm{NiSO}_{4} \cdot 6 \mathrm{H}_{2} \mathrm{O}$ using artificial neural networks. Inż. Chem. Proc. 27(1), 217 - 236. (In Polish).

10. Straszko, J., Strzelczak, A. \& Chrościechowska, J. (2005). Analysis of the decomposition process of $\mathrm{CuSO}_{4} \cdot 5 \mathrm{H}_{2} \mathrm{O}$ under non-isothermal condition. Pol. J. Chem. Tech.7 (2), 54 - 61 .

11. Biedunkiewicz, A., Strzelczak, A. \& Chrościechowska, J. (2005). Non-isothermal oxidation of TiCx powder in dry air. Pol. J. Chem. Tech. 7(4), $1-10$. 
12. Nazarov, A.A. \& Muyukov, R.R. (2003). Nanostructured materials. In W.A. Goddart, D. W. Brenner, S.E. Lyshewski \& G.J. Iafrate (Eds.), Handbook of nanoscience, engineering and technology (pp. 609 - 650). CRC Press LLC.

13. Cushing, B.L., Kolesnichenko, V. L. \& O'Connor, Ch. J.(2004). Recent advances in the liquid-phase syntheses of inorganic nanoparticles. Chem. Rev. 104(9), 3893 - 946. DOI: 10.1002/chin.200447224.

14. Wang, Z. L. (2000). Nanomaterials for nanoscience and nanotechnology. In Z. L. Wang (Ed.) Characterization of nanophase materials (pp. 1 - 11). Wiley-VCH Verlag GmbH.

15. Gleiter, H. (2000). Nanostructured materials: basic concepts and microstructure. Acta Mat. 48(1), 1 - 29. DOI: 10.1016/S1359-6454(99)00285-2.

16. Chung, D.D.L. (2001). Applied materials science. Chapman \&Hall/CRC CRC Press LLC.

17. Richerson, D.W. (2004). Advanced ceramic matarials. In J.K. Wessel (Ed.) Handbook of advanced materials (pp.65 - 88). John Willey \& Sons, Inc., New Jersey.

18. Pampuch, R. (2005). Contemporary ceramic materials. AGH- Uczelniane Wydawnictwo Naukowe, Kraków. (In Polish)

19. Holmberg, K. \& Matthews, A. (2001). Coatings tribology: properties, techniques and application in engineering. Elsevier, New York.

20. Bunshah, R.F. (2001). Handbook of hard coatings; Deposition technologies, properties and application. Noyes Publications,. Park Ridge, New York.

21. Biedunkiewicz, A., Gordon, N., Straszko, J. \& Tamir, S. (2007) Kinetics of thermal oxidation of titanium carbide and its carbon nano-composites in dry air atmosphere. $J$. Therm. Anal. Cal. 88(3), 717 - 722. DOI: 10.1007/s10973-0068222-x.

22. Coats, A.W. \& Redfern, J.P. (1964). Kinetic parameters from thermogravimetric data. Nature. 201, 68 - 69. DOI: 10.1038/201068a0.

23. Mc Culloch, W.S. \& Pitts, W. (1943). A logical calculus of ideas immanent in nervous activity. Bull. Math. Biol. 5(4), 115 - 133. DOI: 10.1007/BF02478259.

24. Widrow, B. \& Hoff, M. (1960). Adaptive switching circuits. In Proceedings of. IRE WESCON Covention Record, Part 4 (pp. 96 - 104).

25. Hopfield, J. (1982). Neural networks and physical systems with emergent collective computational abilities, Proc. Natl. Acad. Sci. U S A. 79 (8), 2554 - 2558. DOI: 10.1073/ pnas.79.8.2554.

26. Cover, T. (1965). Geometrical and statistical properties of systems of linear inequalities with applications in pattern recognition. IEEE Trans. Elec. Comp. 14, 326 - 334. DOI: 10.1109/PGEC.1965.264136.

27. STATISTICA- system description, Statsoft. Retrieved November 1, 2007, from http://www.statsoft.pl

28. STATISTICA NEURAL NETWORKS ${ }^{T M} P L$, Introduction to neural networks, StatSoft. Retrieved November 1, 2007, from http://www.statsoft.pl

29. STATISTICA NEURAL NERWORKS ${ }^{T M}$ PL., Problem guide, StatSoft. Retrieved November 1, 2007, from http:// www.statsoft.pl

30. STATISTICA NEURAL NETWORKS TM PL, StatSoft. Retrieved November 1, 2007, from http://www.statsoft.pl

31. Shimada, S. \& Kozeki, M. (1992). Oxidation of TiC at low temperatures. J. Mat. Sci. 27(7), 1869 - 1875. DOI: 10.1007/BF01107214.

32. Shimada, S. (1996). A thermoanalytical study of oxidation of TiC by simultaneous TGA-DTA-MS analysis. $J$. Mat. Sci. 31(3), 673 - 677. DOI: 10.1007/BF00367884.

33. Shimada, S.(2001). Interfacial reaction on oxidation of carbides with formation of carbon. Sol. St. Ionics. $141-142$, 99 - 104. DOI: 10.1016/S0167-2738(01)00727-5.
34. Sobczyk, K. (1996). Stochastic differential equations. WNT, Warszawa. (In Polish).

35. Hien, T.D. (2003). Numerical analysis of stochastic systems. Prac. Nauk. Pol. Szcz. 579, 21 - 28. (In Polish)

36. Biedunkiewicz, A. \& Wróbel, R. (2004). The XRD study of the nanostructured $\mathrm{TiC} / \mathrm{C}$ and $\mathrm{TiN} / \mathrm{C}$ composites. Rev. Adv. Mat. Sci. 8, $69-72$.

37. Qian-Gang, F., He-Jun, L., Xiao-Hong, S., Ke-Zhi, L., Jian, W. \& Min, H. (2006). Oxidation protective glass coating for $\mathrm{SiC}$ coated carbon/carbon composites for application at 1773 K. Mat. Lett. 60(3), 431 - 434. DOI: 10.1016/ j.matlet.2005.09.006.

38. Lin, Y.J. \& Chen, L.J. (2000). Oxidation of SiC powders in SiC/alumina/zirconia compacts. Ceram. Int. 26(6), 593-598. DOI: 10.1016/S0272-8842(99)00102-9.

39. Kozin, F. (1988). The method of statistical linearization for non-linear stochastic vibration in nonlinear stochastic $d y$ namic engineering system. Springer-Verlag, Berlin. 